Aim of the study: The main aim of this article is the epidemiological analysis of patients treated due to oral and oropharyngeal cancer, with a special interest in the group under the age of 40 , evaluation of the differences in the clinical course of the disease as well as assessment of the treatment results, regarding the age of the affected individuals. Material and methods: 523 individuals affected by oral and oropharyngeal cancer who were treated in the Otolaryngology and Laryngeal Oncology Department between 2000 and 2008. Precise analysis was performed on 360 out of 523 affected individuals, in whom full clinical status was determined; 13 patients were young adults.

The retrospective analysis was created based on case histories, surgical protocols and emergency records.

Results: In young adults there is a markedly increased risk of organ involvement according to the Mann-Whitney U-test analysis $(p=0.044907)$. The probability of recurrence in the group of young adults is also much higher. Analysis of Kaplan-Meier test results indicated that the chance for the lack of recurrence within a 6 -month period was $85.7 \%$; however, the risk of recurrence increased, and after 12 months was equal to the arithmetic data (50\%).

Conclusions: Among young adults there is an increased risk of local recurrence following 12 months after surgical intervention. According to our observations, despite rapid progression and early recurrence in young adults (4/7) the prognosis for both groups is not statistically different.

Key words: oral cavity, oropharyngeal cancer, young adult.

\section{Variable course of progression of oral cavity and oropharyngeal carcinoma in young adults}

\author{
Maciej Szczepan Pabiszczak, Elżbieta Waśniewska, Daniela Mielcarek-Kuchta, \\ Dorota Miętkiewska-Leszniewska, Małgorzata Wierzbicka, Witold Szyfter
}

Otolaryngology and Laryngeal Oncology Department, Poznan University of Medical Sciences, Poznan, Poland

\section{Introduction}

Cancer of the oral cavity is classified as the sixth most common malignancy among all neoplasms of the head and neck region [1]. This particular type of cancer usually occurs in the elderly; however, long-term observations indicate that there is a significant increase in occurrence of this neoplasm in a younger population $[2,3]$. Incidence of oral cancer in individuals under the age of 40 varies from $0.4 \%$ to $5.5 \%[4,5]$. In the late 1970 s, Byers introduced the new meaning of individuals under the age of 30 affected by oral cancer and termed them as "young adults" [6]. Currently, the majority of authors accept this term for affected individuals under the age of $40[7,8]$.

The main aim of this article is the epidemiological analysis of patients treated for oral and oropharyngeal cancer, with a special interest in the group under the age of 40, evaluation of the differences in the clinical course of the disease as well as assessment of the treatment results, regarding the age of the affected individuals.

\section{Material and methods}

This retrospective analysis was created based on case histories, surgical protocols and emergency records. Between 2000 and 2008, 523 individuals affected by oral and oropharyngeal cancer were treated in the Otolaryngology and Laryngeal Oncology Department of the University of Medical Sciences in Poznan, Poland. Full physical examination was performed in each patient; additionally, from 2005, computed tomography (CT) or magnetic resonance imaging (MRI) was also implemented as a part of the initial examination. Evaluation of the primary site of the tumor origin was performed with ultrasonography (USG) in the region of the lymphatic system of the neck. The group of affected patients comprised 455 men, who formed the predominant portion (87\%), and 68 women (13\%).

Precise analysis was performed on 360 out of 523 affected individuals, in whom full clinical status was determined. Out of 360 patients, 13 were young adults, who were from 26 to 36 years old. Clinical characteristics of a group consisting of seven young adults is distinguished in Table 1.

The surgical procedure as the primary method of treatment was performed in 340 patients, while 20 patients were treated with primary radiotherapy/chemotherapy.

\section{Results}

The 523 affected patients were from 28 to 91 years old; the mean age was 59 years (median 56 years). The predominant group consisted of patients between 51 and 60 years of age (46\% out of 241 affected patients). The second largest group of patients comprised patients in their seventh decade of 
Table 1. Complete data of young adults treated in the clinic during 2000-2008

\begin{tabular}{|c|c|c|c|c|c|c|c|}
\hline & & & & Patient's data & & & \\
\hline Initials & D.C. & R.K. & D.Z. & T.K. & A.J. & S.W. & D.J. \\
\hline Age & 36 & 30 & 31 & 28 & 32 & 29 & 26 \\
\hline $\begin{array}{l}\text { Duration } \\
\text { of symptoms } \\
\text { (months) }\end{array}$ & 5 & 4 & 4 & 5 & 4 & 2 & 2 \\
\hline $\begin{array}{l}\text { Additional } \\
\text { diseases/ } \\
\text { anomalies }\end{array}$ & $\begin{array}{c}\text { deppression } \\
\text { hypertension } \\
\text { glucose } \\
\text { intolerance }\end{array}$ & - & - & - & $\begin{array}{c}\text { hypertension } \\
\text { podagra }\end{array}$ & - & - \\
\hline TNM & T3N2MO & T2NOMO & T4N1M0 & T4N1M0 & T4NOMO & T4N2MO & T3N2MO \\
\hline HPV & negative & positive & positive & positive & positive & negative & positive \\
\hline $\begin{array}{l}\text { Cigarettes/ } \\
\text { alcohol }\end{array}$ & no/no & yes/no & no/no & yes/no & yes/yes & no/no & no/no \\
\hline $\begin{array}{l}\text { Family } \\
\text { history }\end{array}$ & $\begin{array}{l}\text { Dad, } \\
\text { testicular } \\
\text { cancer }\end{array}$ & negative & negative & negative & negative & negative & negative \\
\hline $\begin{array}{l}\text { Type of } \\
\text { treatment }\end{array}$ & $\begin{array}{l}\text { radical } \\
\text { forearm } \\
\text { flap }\end{array}$ & $\begin{array}{c}\text { salvage } \\
\text { pectoralis } \\
\text { major flap }\end{array}$ & $\begin{array}{c}\text { radical } \\
\text { forearm flap }\end{array}$ & $\begin{array}{l}\text { non-radical } \\
\text { pectoralis } \\
\text { major flap }\end{array}$ & $\begin{array}{c}\text { radical } \\
\text { antero-lateral } \\
\text { thigh flap }\end{array}$ & $\begin{array}{c}\text { radical } \\
\text { forearm lap }\end{array}$ & radical \\
\hline $\begin{array}{l}\text { Pathological } \\
\text { analysis }\end{array}$ & $\begin{array}{c}\text { squamous } \\
\text { cell cancer G2 }\end{array}$ & $\begin{array}{c}\text { squamous } \\
\text { cell cancer G2 }\end{array}$ & $\begin{array}{l}\text { squamous cell } \\
\text { cancer G2 }\end{array}$ & $\begin{array}{l}\text { squamous } \\
\text { cell cancer G1 }\end{array}$ & $\begin{array}{c}\text { squamous } \\
\text { cell cancer G2 }\end{array}$ & $\begin{array}{l}\text { squamous } \\
\text { cell cancer G1 }\end{array}$ & $\begin{array}{c}\text { squamous } \\
\text { cell cancer } \mathrm{G} 2\end{array}$ \\
\hline $\begin{array}{l}\text { Radiotherapy/ } \\
\text { chemo/ } \\
\text { brachytherapy }\end{array}$ & $\begin{array}{l}\text { radiotherapy/ } \\
\text { chemotherapy }\end{array}$ & $\begin{array}{l}\text { radiotherapy/ } \\
\text { brachytherapy }\end{array}$ & radiotherapy & radiotherapy & $\begin{array}{c}\text { intially } \\
\text { radiotherapy/ } \\
\text { chemotherapy }\end{array}$ & $\begin{array}{l}\text { radiotherapy/ } \\
\text { chemotherapy }\end{array}$ & $\begin{array}{l}\text { radiotherapy/ } \\
\text { chemotherapy }\end{array}$ \\
\hline Observations & $\begin{array}{l}\text { without } \\
\text { local } \\
\text { recurrence } \\
\text { (12 months) }\end{array}$ & $\begin{array}{c}\text { recurrence } \\
\text { after } \\
12 \text { months, } \\
\text { spread to } \\
\text { the lungs }\end{array}$ & $\begin{array}{c}\text { local } \\
\text { recurrence } \\
\text { after } \\
8 \text { months }\end{array}$ & $\begin{array}{c}\text { recurrence } \\
\text { after } \\
12 \text { months, } \\
\text { overall } \\
\text { spread }\end{array}$ & $\begin{array}{l}\text { without } \\
\text { local } \\
\text { recurrence } \\
\text { (16 months) }\end{array}$ & $\begin{array}{l}2 \text { years } \\
\text { without } \\
\text { recurrence }\end{array}$ & $\begin{array}{l}\text { local } \\
\text { reurrence } \\
\text { after } \\
6 \text { months }\end{array}$ \\
\hline
\end{tabular}

life (27\%, 140 patients) and 17\% (89 patients) in their fourth decade. Patients above the age of 70 were the least affected group and comprised 40 (7.6\%) individuals.

Symptoms of the disease in the seven young adults lasted for two to five months (mean 3.7, median 4 months), while in the remaining group the duration of symptoms was from 1 to 12 months (mean 3.6 months, median 3 months). However, the difference was not statistically significant. Based on medical histories, two young individuals (28.6\%) presented with hypertension, diabetes mellitus and gout. In the remaining group of 360 individuals, 160 patients had other accompanying diseases (44.4\%). Again, the difference was not statistically significant. Within the group of young adults, two patients tested positive for the presence of HPV 16 and HPV 18. The group of affected patients above 40 years of age was not tested for the presence of human papillomavirus. None of the affected young patients admitted to alcohol abuse; however, two of them smoked from several up to 20 cigarettes daily. Short exposure time to carcinogens hinders statistical comparison with the rest of the population.

The degree of local advancement in the group of 523 affected patients was graded as T1 in 16 patients (3.1\%), T2 in 72 (13.8\%), T3 in 157 (30\%), and T4 in 278 (53.2\%). Preoperative degree of regional advancement was found to be NO in 215 affected individuals (41\%), N1 in 239 (46\%), N2 in 40 (7.6\%), and N3 in 28 (5.4\%).

The assessment of the degree of local advancement $(T)$ in young individuals gave the following results: $\mathrm{T} 2-1$ patient (14.3\%), T3 -2 patients (28.6\%), T4 - 4 patients (57.1\%). In 360 patients above the age of 40 the results were as follows: T1 - 10 (2.8\%), T2 - 52 (14.4\%), T3 - 110 (30.6\%), T4 - 188 (52.2\%). According to the Mann-Whitney U-test analysis ( $p=0.044907)$, there is a significant difference between groups of young and adult patients. There is a markedly increased risk of organ involvement in young adults (Fig. 1).

Metastases occurred in the lymphatic system of the neck region in five young adults. The distribution of the nodal involvement ( $\mathrm{N}$ ) was as follows: NO - 2 (28.6\%), N1 - 2 (28.6\%), N2 $-3(42.9 \%)$. The analysis of distribution of nodal involvement in the remaining group of 360 individuals gave the following results: N0 - 146 (40.6\%), N1 - 165 (45.7\%), N2 - 29 (8.1\%), N3 - 20 (5.6\%). According to the Mann-Whitney U-test analysis there is no significant difference ( $p=0.29674)$.

No signs of distant metastases $(M)$ were found during the initial examination of young adults. Among the remaining 360 affected individuals, 6 patients (1.6\%) were positive for metastases, but the difference was not statistically significant when compared to the group of young adults. Histo- 


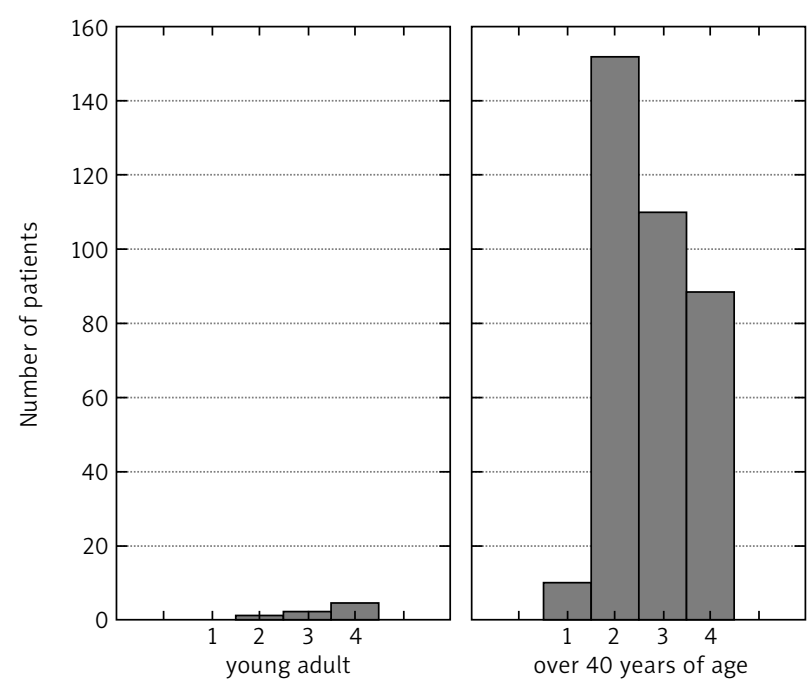

Fig. 1. Degree of organ involvement $T$, in young adults and adults over 40 years of age according to the U-Mann-Whitney analysis

logical analysis confirmed planoepithelial carcinoma in all affected individuals. Grading of each tumor was analyzed in order to confirm the morphological maturity of the lesion. In young adults, the results were as follows: $\mathrm{G} 1-2$ (28.6\%), $\mathrm{G} 2-5(71.4 \%)$. In adults over the age of 40 the results were: G1 - 64 (19.5\%), G2 - 182 (59.1\%), G3 - 70 (21.4\%). No specific tumor grade was determined in 52 patients. Mann-Whitney $U$-test analysis showed no significant difference in this particular group of patients ( $p=0.270129$ ).

One (14.3\%) out of seven young adults was treated with initial radio- and chemotherapy. In the remaining six patients (85.7\%) extensive removal of the primary lesion was performed along with a single free flap reconstruction procedure: three patients had a free flap reconstruction performed using a flap from the cutaneo-fascial region of the forearm, while one patient had a flap acquired from the fronto-lateral part of the thigh. A pedicle flap obtained from the pectoralis major muscle was used in 2 patients. In one individual a flap reconstruction procedure was not deemed necessary. All affected individuals received radiotherapy, chemotherapy or radiochemotherapy post-operatively. One patient received primary radiochemotherapy. Lack of tumor regression was an indication for surgical removal of the tumor. Radiotherapy was the initial method of treatment in 20 (5.6\%) patients from the group of individuals over the age of 40 ; however, in 340 (94.4\%) patients, surgery was the initial method of management. 102 (30\%) out of 340 surgically treated patients underwent a free flap reconstruction. The method of treatment in the group of young adults and those over the age of 40 differed in the aspect of extent and range of reconstruction - extensive surgical treatment along with reconstruction procedures were more frequent in young adults.

The authors performed comparison of treatment results in both groups. Local recurrence of the tumor along with a generalized spread was found in 4 young adults during the 6-24-month period after the operation. The 3 remaining patients showed no recurrence within 24 to 36 months after the surgical treatment. The Wilcoxon/Gehen test showed a statistically significant difference between the treated groups ( $p=0.00498$ ). The group of patients above 40 years

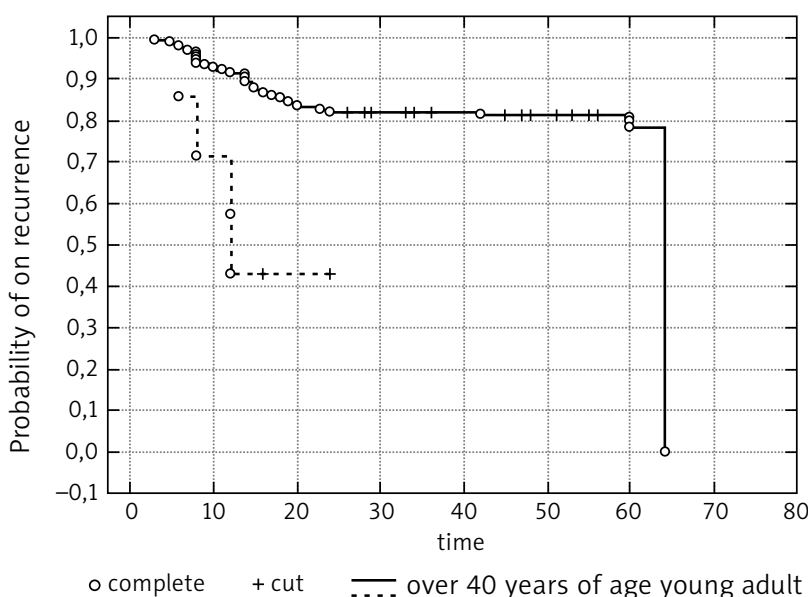

Fig. 2. Probability of absence of local recurrence according to the Kaplan-Meier method for adults and a group of patients over 40 years of age

of age had a higher probability of survival without recurrence as opposed to young adults. According to the analysis, the probability of recurrence in the group of young adults is much higher. Analysis of Kaplan-Meier test results indicated that the chance for the lack of recurrence within a 6-month period was $85.7 \%$; however, the risk of recurrence increased dramatically, and after 12 months was equal to the arithmetic data (50\%) (Fig. 2).

According to the clinical data of the group of adults, the time of follow-up ranged from 18 months to 9 years. Data from the period 2000-2008 indicate that the 5-year survival rate is $67.5 \%$, while the rate of survival longer than 5 years is $33 \%$. No significant difference was found in the survival rate between young adults under the age of 30 , and the adult group.

\section{Discussion}

Despite the fact that smoking and alcohol abuse are the main etiopathological agents of cancer in the older population, only an insubstantial number of young patients admit to them while taking a medical history [4]. Absence of typical environmental factors responsible for the process of cancerous progression turned our attention to the role of other potential causes: immunological deficiency, genetic predispositions, nutritional imbalance, but most importantly, presence of viruses, such as HSV and HPV [9-12]. According to our data, affected patients were not susceptible to the action of genotoxic agents, and only one patient claimed presence of carcinoma in a family member (the father of the affected patient was diagnosed with testicular cancer).

According to the current state of our knowledge, the relationship between the infectious process caused by HPV and carcinoma of the oropharyngeal region is proven. This is an important correlation due to the fact that it provides us with a significant factor of prognosis in the group of young adults infected with HPV. This association is not seen in patients diagnosed with oral cancer, where presence of HPV was not found [13]. According to our data, 2 out of 7 young adults tested positive for the presence of HPV. No local recurrence of the tumor occurred in those patients throughout the two years of follow-up. 
Morphological analysis of oral carcinoma indicates its rapid increase in size and, unfortunately, its unpredictable behavior may lead to metastases to the lymphatic system of the neck. Observation of young adults during the $2-5$ month interval revealed development of symptoms. The primary state of tumor advancement $(T)$ led to an increased risk of metastases to the lymphatic region of the neck in young adults. This risk was not as pronounced in the group of adults [14]. Signs of metastases to the lymphatic system of the neck were diagnosed in 5 affected patients (70\%), while 2 patients were free of lymphatic system involvement in the region of the neck (30\%). The difference in the stage of progression $(\mathrm{N})$ in these specific age groups as well as the difference between these particular groups were not statistically significant.

The tongue is the most frequent site of oral carcinoma in the older population and accounts for nearly $47 \%$ of cases. The next most common site is the oral mucosa (23\%) $[15,16]$. Localization in the region of the floor of the mouth is seen much less frequently, especially in young patients [17]. According to our data, the tongue was the primary location within the group of adults under the age of 40 (4 patients $-57 \%$ ), as well as the floor of the mouth (3 patients $-43 \%$ ); however, in the group of adults the tumor was most commonly confined to the region of the palatal tonsil (46.6\%) and tongue (29\%).

According to the literature it was statistically confirmed that the majority of affected individuals were diagnosed in the first stage of tumor progression [17]. The analysis of our data gave a contradictory result: tumor spread was extensive in $57 \%$ of young adults and in $52 \%$ of patients above the age of 40 , mainly in stages $T 3$ and $T 4$. In young adults, the higher degree of progression was statistically significant when compared with adult patients.

Histological analysis of planoepithelial carcinoma in young adults indicates more aggressive behavior. Some authors suggest that cancer in young adults has a more anaplastic character, leading to a more aggressive course and poorer prognosis [6]; however, according to Holm et al., the morphological degree of progress of oral carcinoma does not correlate with survival and recurrence of the tumor [18].

Amongst our groups of patients, type $G 2$ (without any statistical difference) was predominant; however, in the group of young adults this degree of differentiation correlated with the number of local recurrences (5/3).

Numerous assessments of survival rate studies of those affected by oral cancer revealed a discrepancy of the results in young adults and the older population. It is important to emphasize the fact that in our study, young adults were not free of other diseases (2/7). Singh et al. confirmed similar observations and noted that additional maladies could negatively influence the remission as well as survival rate of affected patients [19]. According to our study, the group of patients under 40 years of age was affected by other diseases in $27.6 \%$ of cases, and adults in $44.4 \%$.

Infrequent occurrence of cancer in the young population makes it quite challenging to uncover the etiopathological factors and retards early diagnosis, even though symptoms of carcinoma are similar to those in the older population. According to Lund and Howard, the cancer diagnosed in young adults could be the reason for the high mortality rate (75\%)
[20]. Our data revealed that the diagnosis of the tumor in young adults was delayed for 2 to 5 months; however, the mortality rate was $57 \%$. An extended qualifying period for surgical treatment and minimally invasive tumor resections could also lead to an increased frequency of local recurrence [21]. Some authors point to the fact that oral cancer in young patients is more aggressive and requires more radical treatment [20]. Burzyński et al. reported good treatment outcomes in those patients who were surgically treated in the early phase of tumor development [15]. However, others did not note any significant difference between these two age groups [22]. According to the clinical data, performed surgical treatment included extensive resection of the tumor and required reconstruction of the area with pedicle flaps or free flaps with the use of microvascular anastomoses in 6 out 7 young adults (85\%).

Retrospective analysis with a control group that assessed the entire adult population showed a 5-year survival rate of $39 \%$ [23]. High frequency of local recurrence in the young population was confirmed; however, differences in 5-year survival rates were not statistically significant when compared with results obtained by Von Doersten et al., who did not find a correlation with age as a factor that could lead to local recurrences [14, 24, 25]. From 1985 to 1996, Funk et al. obtained data of young patients ( 35 years old or younger) affected by carcinoma of the head and neck region. Comparison of the above-mentioned group with patients older than 65 years revealed that in the first stage of the disease, the survival rate in the younger group was higher [17].

Our attention focused on rapid progression of tumor in 2 young patients following 6 to 8 months after the initial treatment. In 3 other patients, recurrence appeared within 12 months after treatment as distal metastases to the lung region. All of these patients died in less than 2 years ( $57 \%$ failures).

In conclusions, oropharyngeal cancer in young adults is considered as a rare pathological phenomenon. This statistic is supported by the fact that during the past decade, only 13 out of 523 people diagnosed with this type of cancer were young patients.

Higher degree of organ involvement (T) was confirmed in young adults in the initial diagnosis. Among young adults there is an increased risk of local recurrence following 12 months after surgical intervention.

According to our observations, despite rapid progression and early recurrence in young adults (4/7) the prognosis for both groups is not statistically different. Application of appropriate aggressive treatment methods is the key to successful cancer management.

\section{The authors declare no conflict of interest.}

\section{References}

1. Parkin DM, Pisani P, Ferlay J. Estimates of the worldwide incidence of eighteen major cancers. Int J Cancer 1993; 54: 594-606.

2. Schantz SP, Yu GP. Head and neck cancer incidence trends in young Americans, 1973-1997, with a special analysis for tongue cancer. Arch Otolaryngol Head Neck Surg 2002; 128: 268-74. 
3. Shiboski CH, Schmidt BL, Jordan RC. Tongue and tonsil carcinoma: increasing trends in the U.S. population ages 20-44 years. Cancer 2005; 103: 1843-9.

4. Sankaranarayanan R, Mohideen MN, Nair MK, Padmanabhan TK. Aeti ology of oral cancer in patients less than or equal to 30 years of age. Br J Cancer 1989; 59: 439-40.

5. Venables CW, Craft IL. Carcinoma of the tongue in early adult life. Br J Cancer 1967; 21: 645-50.

6. Byers RM. Squamous cell carcinoma of the oral tongue in patients less than thirty years of age. Am J Surg 1975; 130: 475-8.

7. Friedlander PL, Schantz SP, Shaha AR, Yu G, Shah JP. Squamous cell carcinoma of the tongue in young patients: a matched-pair analysis. Head Neck 1998; 20: 363-8.

8. Sarkaria JN, Harari PM. Oral tongue cancer in young adults less than 40 years of age: rationale for aggressive therapy. Head Neck 1994 16: 107-11.

9. Wanebo HJ, Jun MY, Strong EW, Oettgen H. T cell deficiency in patients with squamous cell cancer of the head and neck. Am J Surg 1975; 130: 445-51.

10. Sarna G, Tomasulo P, Lotz MJ, Bubinak JF, Shulman NR. Multiple neoplasms in 2 siblings with a variant form of Fanconi's anemia. Cancer 1975; 36: 1029-33.

11. Notani PN, Jayant K. Role of diet in upper aerodigestive tract cancers. Nutr Cancer 1987; 10: 103-17.

12. Kumari TV, Vasudevan DM, Ravindran A, Ramani P, Vijayakumar T. Demonstration of HSV 1 antigen with oral cancer by immunofluroscence and immunoperoxidase technology. J Exp Pathol 1987; 3: 75-85.

13. Sisk EA, Bradford CR, Jacob A, et al. Human papillomavirus infection in "young" versus "old" patients with squamous cell carcinoma of the head and neck. Head Neck 2000; 22: 649-57.

14. Veness MJ, Morgan GJ, Sathiyaseelan Y, Gebski V. Anterior tongue cancer and the incidence of cervical lymph node metastases with increasing tumour thickness: should elective treatment to the neck be standard practice in all patients? ANZ I Surg 2005; 75: 101-5.

15. Burzynski NJ, Flynn MB, Faller NM, Ragsdale TL. Squamous cell carcinoma of the upper aerodigestive tract in patients 40 years of age and younger. Oral Surg Oral Med Oral Pathol 1992; 74: 404-8.

16. Iype EM, Pandey M, Mathew A, Thomas G, Sebastian P, Nair MK. Oral cancer among patients under the age of 35 years. J Postgrad Med 2001; 47: 171-6.

17. Funk GF, Karnell LH, Robinson RA, Zhen WK, Trask DK, Hoffman HT. Presentation, treatment, and outcome of oral cavity cancer: a National Cancer Data Base report. Head Neck 2002; 24: 165-80.

18. Holm LE, Lundquist PG, Silfverswärd C, Sobin A. Histological grading of malignancy in squamous cell carcinoma of the oral tongue. Acta Otolaryngol 1982; 94: 185-92.

19. Singh B. Squamous cell carcinoma and FA. In: Owen J, Frohnmayer L, Eiler ME (eds.). Fanconi Anemia, Standards for Clinical Care. 2nd ed. Fanconi Anemia Research Fund, Oregon 2003.

20. Lund VJ, Howard DJ. Head and neck cancer in the young: a prognostic conundrum? J Laryngol Otol 1990; 104: 544-8.

21. Son YH, Kapp DS. Oral cavity and oropharyngeal cancer in a younger population. Cancer 1985; 55: 441-4.

22. Clarke RW, Stell PM. Squamous carcinoma of the head and neck in the young adult. Clin Otolaryngol 1992; 17: 18-23.

23. Macfarlane GJ, Sharp L, Porter S, Franceschi S. Trends in survival from cancers of the oral cavity and pharynx in Scotland: a clue as to why the disease is becoming more common? Br J Cancer 1996; 73 : 805-8.

24. Vargas H, Pitman KT, Johnson JT, Galati LT. More aggressive behavior of squamous cell carcinoma of the anterior tongue in young women. Laryngoscope 2000; 110 (10 Pt 1): 1623-6.

25. Argiris A, Brockstein BE, Haraf DJ, et al. Competing causes of death and second primary tumors in patients with locoregionally advanced head and neck cancer treated with chemoradiotherapy. Clin Cancer Res 2004:10: 1956-62.

\section{Address for correspondence}

Dr Maciej Szczepan Pabiszczak

Otolaryngology and Laryngeal Oncology Department

Poznan University of Medical Sciences

Przybyszewskiego 49

60-355 Poznań, Poland

tel. +48618691387

fax +48 618691690

e-mail: maciejpabi@poczta.onet.pl

Submitted: $\quad$ 10.09.2012

Accepted: $\quad 28.11 .2012$ 